Article

\title{
A Cloud-Based Mapping Approach Using Deep Learning and Very-High Spatial Resolution Earth Observation Data to Facilitate the SDG 11.7.1 Indicator Computation
}

\author{
Natalia Verde *(D), Petros Patias (D) and Giorgos Mallinis (D)
}

Citation: Verde, N.; Patias, P.; Mallinis, G. A Cloud-Based Mapping Approach Using Deep Learning and Very-High Spatial Resolution Earth Observation Data to Facilitate the SDG 11.7.1 Indicator Computation. Remote Sens. 2022, 14, 1011. https:// doi.org/10.3390/rs14041011

Academic Editor: Tri Dev Acharya

Received: 21 January 2022

Accepted: 16 February 2022

Published: 18 February 2022

Publisher's Note: MDPI stays neutral with regard to jurisdictional claims in published maps and institutional affiliations.

Copyright: (C) 2022 by the authors. Licensee MDPI, Basel, Switzerland. This article is an open access article distributed under the terms and conditions of the Creative Commons Attribution (CC BY) license (https:// creativecommons.org/licenses/by/ $4.0 /)$.
Laboratory of Photogrammetry and Remote Sensing (PERS lab), School of Rural and Surveying Engineering, Aristotle University of Thessaloniki, 54124 Thessaloniki, Greece; patias@auth.gr (P.P.); gmallin@topo.auth.gr (G.M.)

* Correspondence: nverde@topo.auth.gr

\begin{abstract}
As urbanized areas continue to expand rapidly across all continents, the United Nations adopted in 2015 the Sustainable Development Goal (SDG) 11, aimed at shaping a sustainable future for city dwellers. Earth Observation (EO) satellite data can provide at a fine scale, essential urban land use information for computing SDG 11 indicators in order to complement or even replace inaccurate or invalid existing spatial datasets. This study proposes an EO-based approach for extracting large scale information regarding urban open spaces (UOS) and land allocated to streets (LAS) at the city level, for calculating SDG indicator 11.7.1. The research workflow was developed over the Athens metropolitan area in Greece using deep learning classification models for processing PlanetScope and Sentinel-1 imagery, employing freely-available cloud environments offered by Google. The LAS model exhibited satisfactory results while the best experiment performance for mapping UOS, considering both PlanetScope and Sentinel-1 data, yielded high commission errors, however, the cross-validation analysis with the UOS area of OpenStreetMap exhibited a total overlap of $67.38 \%$, suggesting that our workflow is suitable for creating a "potential" UOS layer. The methodology developed herein can serve as a roadmap for the calculation of indicator 11.7.1 through national statistical offices when spatial data are absent or unreliable.
\end{abstract}

Keywords: google earth engine; land use; land cover; very-heigh resolution; planetscope; synthetic aperture radar; sentinel-1; urban open spaces; road network; OpenStreetMap

\section{Introduction}

Urban areas cover $7.6 \%$ of the global land mass, approximately half the size of the European Union [1], and already hold the majority of the world's population [2], which is expected to increase by $10 \%$ until 2030, from a current 7.7 billion to 8.5 billion [3].

As urbanized areas continue to expand rapidly across all continents, sustainable and successful management of urban growth is essential at the local, national, and even international level. In 2015, United Nations (UN) Member States, adopted Sustainable Development Goal 11 (SDG 11), as part of the 2030 UN Sustainable Development Agenda, to "make cities and human settlements inclusive, safe, resilient and sustainable", indicating that there is currently a universal realization and necessity for actions and measures that could improve the quality of urban environments.

Urban open spaces can provide multiple material and non-material benefits to city inhabitants through their environmental and social functions. They can improve the environmental quality of the city and also bring positive contributions to people's quality of life [4]. Urban open spaces can provide multiple benefits to society, enhance the social life and mental/physical heath of city dwellers, increase the attractiveness of cities through their aesthetic appeal, recreational and historical values, mitigate urban heat effects and 
associated thermal discomfort, remove atmospheric pollutants, host biodiversity and regulate stormwater flow [5-9].

Considering the importance of urban open spaces for shaping future sustainability of cities, a relevant SDG indicator (11.7.1) was formulated to monitor progress, inform policy and ensure accountability of all stakeholders against the SDG 11 Target 11.7, regarding open public spaces and its accessibility to all. In 2018, UN-HABITAT provided a technical document describing the steps and potential data sources for the computation of indicator 11.7.1 as well as the conceptual background of the estimation process [10].

The diverse list of data sources for identifying land characterized as a potential public space, according to indicator 11.7.1, includes city open space and street databases (identified as the most accurate source), local knowledge, editable and open-source geographic databases, existing digital globes, and finally products and analytical databases providing geographic and quantitative dimensions of urban expansion, resulting from remote sensing, Geographic Information Systems (GIS) and statistical analysis as well as EO satellites.

Yet, indicator 11.7.1 remains classified as Tier II, indicating a lack of operationalization for the provision of regular, standardized, open and comparable data produced by countries. As existing computation workflows allow for simple format reporting efficiently at regular intervals, bottlenecks can be identified when considering the use of existing spatial and EO products. Challenges relate to spatial and thematic coverage across regions, data integration collected from different domains and sources, consistent class terminology, variations in spatial data quality and completeness, information gaps over specific attributes and scale of the data [11-14].

EO satellite data is considered a cost-effective, consistent and systematic data source to support policies and actions aimed at improving urban environmental sustainability especially over data-scarce areas $[12,15,16]$. In line with this prospect, the UN-Habitat suggests the use of freely available EO satellite data from Landsat and Sentinel missions for delineating potential public urban open spaces. Yet, while medium-low resolution open and free earth observations (15-30 m), can offer valuable insights useful for policy makers and city managers [14], constraints related to the relatively coarse scale of the data, can lead to relatively low accuracy in capturing human activity within complex urban areas, as for example, roads and buildings [17,18].

The Landsat alike data often results in underestimation of smaller open spaces [11] while even at the block level, building detection remains challenging with 30-m resolution imagery and is feasible only with the finer 10-m pixels from Sentinel-2 observations [19]. Moreover, with average street widths in cities measuring around $10 \mathrm{~m}$ [20], the use of data with a spatial resolution greater than $10 \mathrm{~m}$ is crucial, for correctly representing the land allocated to streets according to the UN instructions.

With the rapid development of commercial, very-high spatial resolution (VHR, $\leq 4 \mathrm{~m}$ ) satellite data following the launch of the IKONOS satellite in 1999, it is now possible to identify textural, contextual and geometrical information of objects [19], opening new opportunities to extract urban land use information at an extremely detailed level [21,22]. Miniaturized satellites, initially introduced as low-cost space research and engineering projects, paved the way to constellations providing cost-effective high temporal and spatial resolution global coverage data [23]. PlanetScope [24], operated by Planet, represents a constellation of approximately 130 satellites, capable of imaging the entire land surface of Earth daily with approximately $3 \mathrm{~m}$ spatial resolution in the visible-near-infrared portion of the electromagnetic spectrum.

Yet, extraction of urban land use is not a straightforward process, since, contrary to land cover relating only to information regarding physical characteristics of the urban environment, land-use also reflects functional attributes of urban areas [25]. Often, due to the high complexity of the urban environment, different land use types may be composed of identical low-level ground objects, bearing extremely similar spectral and textural responses (e.g., parking lots and roads), or on the other hand, the same land use types (e.g., buildings) may be composed of features that vary widely spectrally and spatially [26]. The EO 
classification task faces further challenges when considering the extraction of semantically abstracted functional areas, as in the case of open spaces, that may be decomposed to park, garden, playground, public beach, riverbank and waterfront land use types [27], each formed by spatially aggregated, diverse geographic objects. For example, a median strip is a public open space (according to the UN typology), however, green vegetation in the form of street trees is not. Additionally, streets covered by asphalt are a public open space according to the UN, yet parking lots (also covered by asphalt) are not. Therefore, it is important to develop robust and reliable urban land use classification workflows by effectively exploiting the spatial information inherent in very-high spatial resolution EO data [18].

Traditional classification workflows operating at the pixel level and considering lowlevel features, such as spectral, textural, geometrical, and contextual features, may lead to lower classification accuracies when extracting complex land use classes [28,29]. A more efficient approach relies on the adoption of the object-based paradigm for land-use classification over urban area images, facilitating the use of both within-object low-level features (e.g., spectral, texture, shape) and between-object higher level semantic features (e.g., connectivity, contiguity) [18], but still employing again limited use of the semantic features available in EO images [30].

In recent years, the emergence of advanced deep learning classification methods, has facilitated urban land use classification, allowing extraction of slightly abstract level classes at a deeper level, without human-designed features or rules [18,31]. Through the use of multi-layer neural networks, the most representative and discriminative features are learnt end-to-end in succession, hierarchically [32]. Thus far, few studies have used EO satellite data in conjunction with deep learning for extracting individual types of urban open public spaces, either focusing on areas with vegetation cover, or areas allocated to streets, both needed for the computation of the 11.7.1 indicator.

$\mathrm{Xu}$ et al. [33] used the HRNet deep learning architecture along with $1 \mathrm{~m}$ satellite imagery to classify open spaces with vegetation cover using spectral and phenological features. Chen et al. [28] proposed a new deep learning architecture, for mapping parks and other "green spaces," including plant life, water and other kinds of natural environments, using Sentinel-2 $10 \mathrm{~m}$ bands. In a study focused on road extraction [34], a U-NET based deep learning architecture was employed for extracting roads in RGB satellite images of $1.2 \mathrm{~m}$ spatial resolution, achieving extremely high precision and recall rates. Although accomplishing excellent accuracy, urban land cover mapping using deep learning requires high computational power, owing not only to the finer spatial resolution of the processed data, but also to the large scale of urban agglomerations [11]. In recent years, the emergence of cloud computing platforms has provided the solution to this problem by delivering flexible processing power, memory, disk size and applications as on-demand payable services [35]. A study by Huerta et al. [36] used a deep learning architecture based on U-NET, which was run on the free Google Colab cloud platform, for mapping UGS in Worldview $0.5 \mathrm{~m}$ resolution imagery. The authors used RBG and NIR bands, spectral indices and UGS samples from OpenStreetMap and National data, for the city of Beijing.

In this study, the challenge of extracting essential land use information for calculating indicator 11.7.1 based on classification of EO satellite data is addressed. The core portion of the analysis relies on the use of deep learning for classification of VHR PlanetScope imagery in the freely-available cloud environments of Google Colaboratory and Google Earth Engine (GEE), using open GIS data from the OpenStreetMap (OSM) dataset and the Copernicus High Resolution Layer (HRL) "Imperviousness". The methodology developed herein can serve as a roadmap for the calculation of the indicator by national statistical offices.

\section{Materials and Methods}

\subsection{Study Area}

For successfully reporting on SDG indicators nationwide, UN-Habitat released a technical document to provide guidance for each country to create a statistical representation 
of its own cities, called the National Sample of Cities [37]. The method is based on a stratified sampling of cities, which are grouped based on criteria such as population, city area, geographical location, city functionality and economical and political importance.

However, in this study it was decided to choose the Athens Metropolitan Area (AMA), as a representative city for Greece. Located in the region of Attica, the AMA is one of the most important administrative regions in Greece. Apart from including the country's capital, Athens, it is also the country's largest metropolitan area, covering approximately $400 \mathrm{~km}^{2}$, and hosts around $36 \%$ of the country's population [38,39]. In addition, the broader area of Athens is covered by areas with highly diverse landscapes, from areas exhibiting homogenous compact urban morphology, to dispersed settlements intermixed with factories and farms [40]. This made the AMA an ideal area for developing a methodology that can be transferred, in the future, to multiple urban environments found in various Greek cities.

Since the physical boundaries of the AMA are unknown and will be defined in the process developed, the study area was defined by the bounding box surrounding the mainland of the Attica region (Figure 1), including the broader area of the AMA.

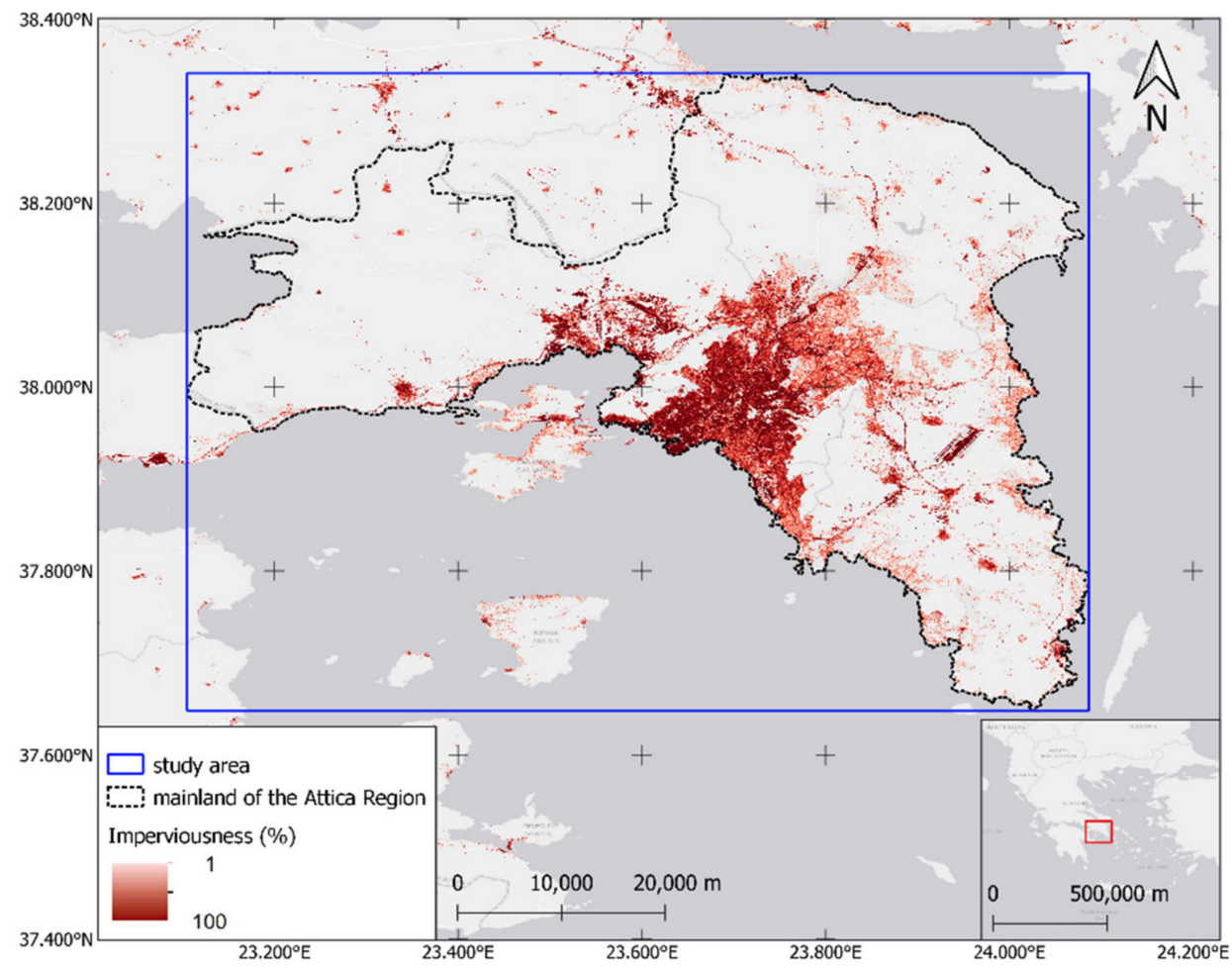

Figure 1. The study area defined, along with the Copernicus "Imperviousness" layer for the broader Athens Metropolitan area. Basemap: Esri.

\subsection{Overall Workflow}

The methodology developed in this study, is in general, a three-step process, as suggested by the UN consisting of (a) delimiting the built-up area of the city (urban extent), (b) mapping urban open spaces (UOS), and (c) estimating the total area of land allocated to streets (LAS) [41].

The indicator is calculated using the following formula, combining the individual information extracted at each step:

$$
\text { Indicator }(\%)=\frac{\mathrm{UOS}_{\mathrm{S}}+\mathrm{LAS}_{\mathrm{S}}}{\mathrm{BUILT}_{\mathrm{S}}}
$$


where $\mathrm{UOS}_{\mathrm{s}}$ is the total surface of urban open spaces, $\mathrm{LAS}_{\mathrm{s}}$ represent the total surface of land allocated to streets and BUILT $T_{S}$ refers to the total surface of the built-up area, in the total urban extent.

Each step is treated as a separate problem and in the end all results are combined for the final computation of indicator 11.7.1. The first step was based on the UN instructions and the Copernicus impervious cover product. The second step involved spatial analysis to map UOS of the urban extent, using very-high resolution PlanetScope imagery, Sentienel-1 imagery, and deep learning. The last step involved the spatial analysis to map the land of the urban extent that is allocated to streets, again making use of the PlanetScope imagery and deep learning.

To facilitate the time and computationally demanding training of the deep learning networks developed in this study, freely available computing resources by Google were used. More specifically, resources accessible through the Google Colaboratory ("Colab") service were used and include memory and multiple CPUs and GPUs, which vary, depending on usage by users [41]. Colab is a hosted Jupyter notebook service, that requires no setup and is customized for machine learning and data analysis. In addition, Colab provides direct connection to the Google Earth Engine (GEE) [42], a cloud platform for geospatial analysis that is also freely provided for research applications and was employed supplementally in this study for processing satellite data. The code developed on Colab runs on Python 3 and the DL networks were trained and applied using the TensorFlow library (v.2.6.0) [43] and Keras [44], a high-level API to build and train models in TensorFlow.

\subsection{Satellite Data}

The datasets used in this study were mainly satellite imagery (PlanetScope and Sentinel-1) for mapping the LAS and UOS.

PlanetScope sensors acquire 12-bit multispectral images in the red, green, blue and NIR portion of the electromagnetic spectrum, with 3.7-4.1 m spatial resolution, in low-earth sun-synchronous orbits [45]. For this study, the Planet Surface Reflectance Product [24], was employed based on images processed to bottom-of-atmosphere (BOA) reflectance using the $6 \mathrm{~S}$ radiative transfer code [46]. A color balanced average mosaic was created, from images acquired during summer 2020 (from 27 October 2020 to 2 September 2020), covering the urban extent of the AMA, as calculated in the first step of the process.

The Sentinel-1 (S1) satellites are C-band microwave Synthetic Aperture Radars, conFogiured with dual polarization $(\mathrm{VV}, \mathrm{VH})$ interferometric wave modes and an effective revisit of 6 days. The Ground Range-Detected (GRD) products, which are available in GEE in Analysis Ready Data (ARD) format, are radiometrically calibrated and orthocorrected, using SRTM-30 or ASTER digital elevation models, and are offered in geo-coded backscattering coefficients $\left(\sigma_{0}\right)$ [47].

\subsection{Ancillary Data and Preprocessing}

Apart from satellite imagery, freely-available geographic databases were accessed for obtaining ancillary information regarding land use and land cover. The Copernicus High Resolution Layer (HRL) "Imperviousness" of 2018 was used for delineating the urban extent of AMA, and OpenStreetMap (OSM) data were selected for creating UOS and LAS reference samples.

The HRL Imperviousness is a raster product available to Europe, that depicts areas sealed with artificial cover, including the level of soil sealing per pixel for particular reference years. For the 2018 product, the pixel size was $10 \mathrm{~m}$, generated by using a semiautomated classification of maximum Normalized Difference Vegetation Index (NDVI) mosaics of satellite images and is freely available online [48].

OpenStreetMap (OSM) [49] is a crowdsourced spatial database that can provide a detailed representation of land use and land cover (LULC). Although its completeness and correctness may vary across regions, it has been used in studies for collecting reference data for land cover mapping $[50,51]$. Furthermore, the fine scale offered by OSM, representing 
objects up to mid-sized buildings in cities, has allowed for studies to use OSM information as reference data for mapping road networks [52], as well as urban open spaces [11,12,53,54]. OSM was selected in this study for the automated generation of samples. Data queries were created using the Overpass API [55], to obtain the appropriate OSM layers representing UOS and LAS (Table 1), according to the UN, for the AMA. Layers that were not possible to distinguish in the PlanetScope imagery (i.e., galleries, passages and sidewalks), were not considered for the analysis.

Table 1. UN UOS and LAS reference classes and corresponding OSM keys/tags queried.

\begin{tabular}{|c|c|c|c|c|c|}
\hline \multicolumn{3}{|c|}{ UOS } & \multicolumn{3}{|c|}{ LAS } \\
\hline \multirow{2}{*}{$\begin{array}{c}\text { UN Reference } \\
\text { Class }\end{array}$} & \multicolumn{2}{|c|}{ OSM Query } & \multirow{2}{*}{$\begin{array}{c}\text { UN Reference } \\
\text { Class }\end{array}$} & \multicolumn{2}{|c|}{ OSM Query } \\
\hline & OSM Key & OSM Tag & & OSM Key & OSM Tag \\
\hline Parks & leisure & park & & highway & road \\
\hline Recreational areas & landuse & recreation_ground & Streets / Avenues / & highway & living_street \\
\hline Playgrounds & leisure & playground & Boulevards & highway & residential \\
\hline \multirow{3}{*}{ Riverfronts } & natural & sand & Pavements & highway & pedestrian \\
\hline & natural & shingle & & cycleway & track \\
\hline & natural & sand & B1cycle paths & cycleway & lane \\
\hline \multirow[t]{2}{*}{ Waterfronts } & man_made & breakwater & Traffic island & traffic_calming & island \\
\hline & man_made & pier & Roundabouts & junction & roundabout \\
\hline \multirow[t]{3}{*}{ Beaches (public) } & natural & beach & & highway & service \\
\hline & boundary & national_park & & highway & tertiary_link \\
\hline & boundary & protected_area & & highway & secondary_link \\
\hline \multirow[t]{3}{*}{ Civic parks } & landuse & forest & OSM tags added & highway & primary_link \\
\hline & natural & wood & by authors & highway & unclassified \\
\hline & leisure & nature_reserve & & highway & tertiary \\
\hline Gardens (public) & leisure & garden & & highway & secondary \\
\hline \multirow[t]{3}{*}{ Squares and Plazas } & place & square & & highway & primary \\
\hline & landuse & cemetery & & & \\
\hline & amenity & grave_yard & & & \\
\hline \multirow{4}{*}{$\begin{array}{c}\text { OSM tags added } \\
\text { by authors }\end{array}$} & leisure & stadium & & & \\
\hline & leisure & dog_park & & & \\
\hline & landuse & village_green & & & \\
\hline & landuse & orchard & & & \\
\hline
\end{tabular}

\subsection{Processing}

\subsubsection{Built-Up Area and Urban Extent}

The first step of the methodology involved the delineation of the urban cluster. According to the instructions developed by the UN, the boundary of the urban cluster is defined morphologically, based on the density of impervious cover and a walking window filter for classifying the urbanness of each pixel. For a study area defined, and by using a 1-km2 circle around individual pixels, each pixel was classified as urban or not. If more than $25 \%$ of pixels in the circle are covered by impervious surfaces, then that pixel is classified as part of the urban cluster. By using this method, the urban cluster is delineated coarsely and small changes in impervious cover will not affect its extent. Therefore, instead of classifying the latest Landsat imagery to obtain impervious cover as suggested by the UN, the Imperviousness HRL of 2018 was employed as a substitute in this study, since it is a validated product, with a higher spatial resolution $(10 \mathrm{~m})$ than Landsat imagery and depicts the proportion of sealed soil per pixel. The Imperviousness layer is dated only 2 years before the date of this analysis and was used based on the assumption that built-up areas rarely convert back to natural surfaces and change very slowly in developed metropolitan areas, such as the AMA. The walking window filter was applied in the bounding box of the mainland Athens region, and the largest resulting blob was defined as the urban extent of the AMA. 


\subsubsection{Urban Open Space}

Detection and delineation of open spaces within cities is a considerably complex task given the diversity of UOS in size, cover and shape. Indicatively, the size of UOS acquired from OSM for the AMA, ranged between approximately $50 \mathrm{~m}^{2}$ and $1.1 \mathrm{~km}^{2}$, with a median value of $2500 \mathrm{~m}^{2}$, excluding fringe open spaces (forest and shrubland at the fringe of the urban extent) which are not incorporated into the UN definition. Hence, the use of VHR PlanetScope imagery combined with a DL network was considered essential in this step.

U-NET [56] is an algorithm for image semantic segmentation which requires fewer training samples than other architectures, as it internally performs data augmentation, and is relatively fast to train. It is comprised of 23 convolutional layers in an encoder-decoder composition (Figure 2), combining high-level semantic details with low-level information.

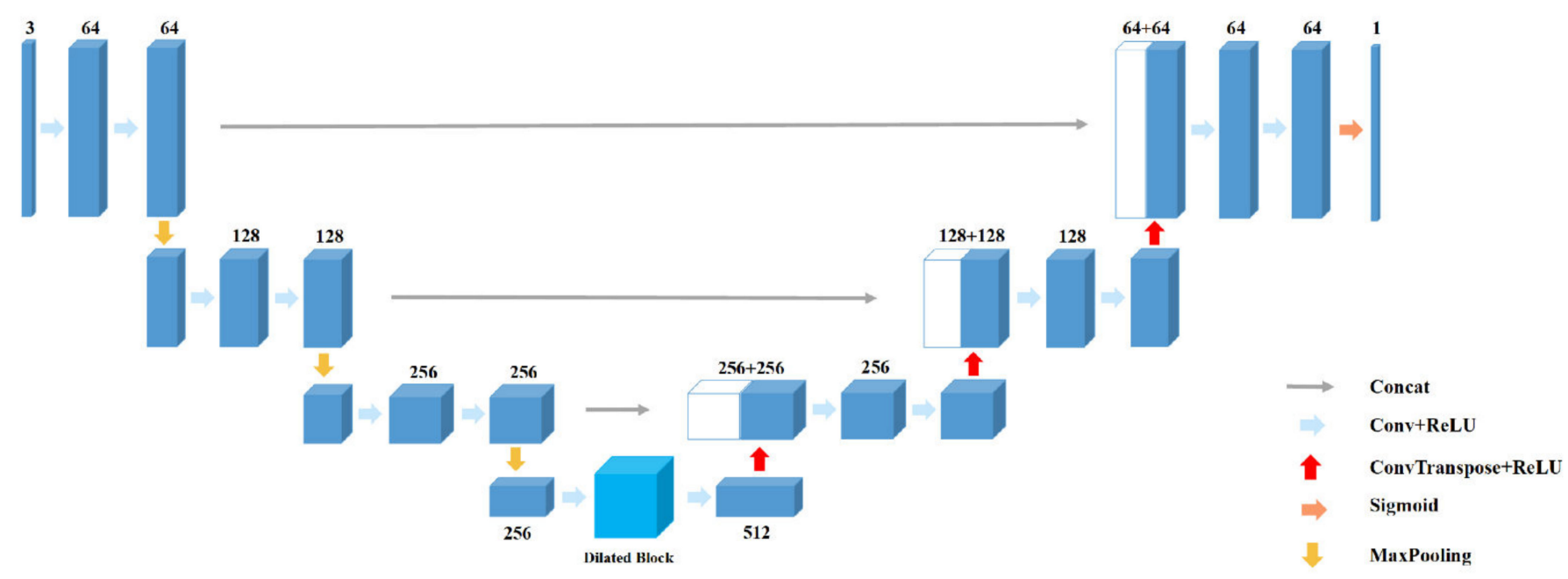

Figure 2. The U-NET architecture [33].

Due to the scarcity of reference data, U-NET and U-NET-based DL architectures were recently used by other studies for mapping open green spaces in cities [33,36]. Additionally, samples for UOS, when approached as a binary problem, exhibit imbalances in terms of pixels covered by UOS and background pixels. This problem has also been addressed previously by using the appropriate loss function. More specifically, Huerta et al. [36] used the dynamic U-NET architecture, the Dice coefficient as a loss function, to solve the sample imbalance problem, and 24,665 patches of $256 \times 256$ pixels (in $0.5 \mathrm{~m}$ resolution), which were split into $85 \%$ for training and $14 \%$ for validation. Likewise, Xu et al. [33] compared different networks, including U-NET and employed the Focal Tversky loss function (an improved version of the Dice loss) to solve the sample imbalance problem. They utilized the Adam optimizer, 1248 training and 312 validation patches and trained for 100 epochs. Chen et al. [28] used Senintel-2 imagery, a custom architecture, SGD optimizer with a learning rate decay, 4550 training and 975 validation image patches, with a size of $512 \times 512$ pixels (in $10 \mathrm{~m}$ resolution).

Consequently, bearing in mind the similarities with the problem of the present study, it was decided to use U-NET as a DL architecture in the UOS-extraction step. In addition, apart from the PlanetScope mosaic, other complementary data were used for UOS mapping. The Normalized Difference Vegetation Index (NDVI) was calculated from the PlanetScope bands to enhance greenness of UOS. Furthermore, S1 GRD SAR data, available from the GEE platform in geo-coded backscattering coefficients $\left(\sigma_{0}\right)$, were used. Data were filtered for the same period of the PlanetScope images and derived images were further mosaicked using a median composite technique. Likewise, the building height index was utilized 
to aid the distinction between buildings and gray UOS. The building height index was calculated using the equations [57]:

$$
\begin{gathered}
\ln \mathrm{H}=\mathrm{a} * \mathrm{VVH}^{\mathrm{b}}+\mathrm{c} \\
\mathrm{VVH}=\mathrm{VV} * \gamma^{\mathrm{VH}}
\end{gathered}
$$

where $\mathrm{a}=-23.61, \mathrm{~b}=-0.06, \mathrm{c}=26.10$ and $\gamma=5$, are parameters calculated by a sensitivity analysis in [57]. The NDVI and building height were added as bands to the PlanetScope image in order to be used as features in the DL network.

Training and validation samples were created by generating a $512 \times 512$ pixel-size $\left(2.36 \mathrm{~km}^{2}\right)$ grid on the PlanetScope image, covering the urban extent area [36]. From the patches intersecting the AMA extent, 150 were randomly selected for generating the training and validation patches within them. The patches were randomly split by a $70 / 30$ percentage ratio and 105 patches were selected for training and 45 for validation (Figure 3). In each patch, manual editing was performed through photointerpretation of Google Earth imagery to improve the OSM UOS vector file where necessary. The corrected UOS file was finally rasterized to $3 \mathrm{~m}$. Within the 105 training patches, 2500 patches of $589,824 \mathrm{~m}^{2}$ each $(256 \times 256$ pixels in the resampled rasterized image) were randomly created and 1071 were randomly created within the 45 validation patches, respectively.

a) Urban open space (UOS) samples

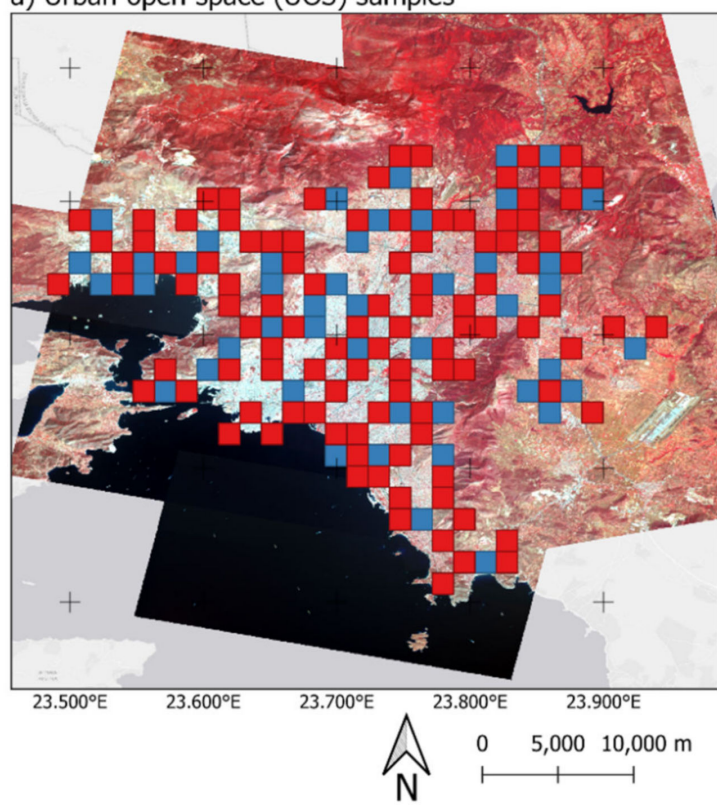

b) Land allocated to streets (LAS) samples

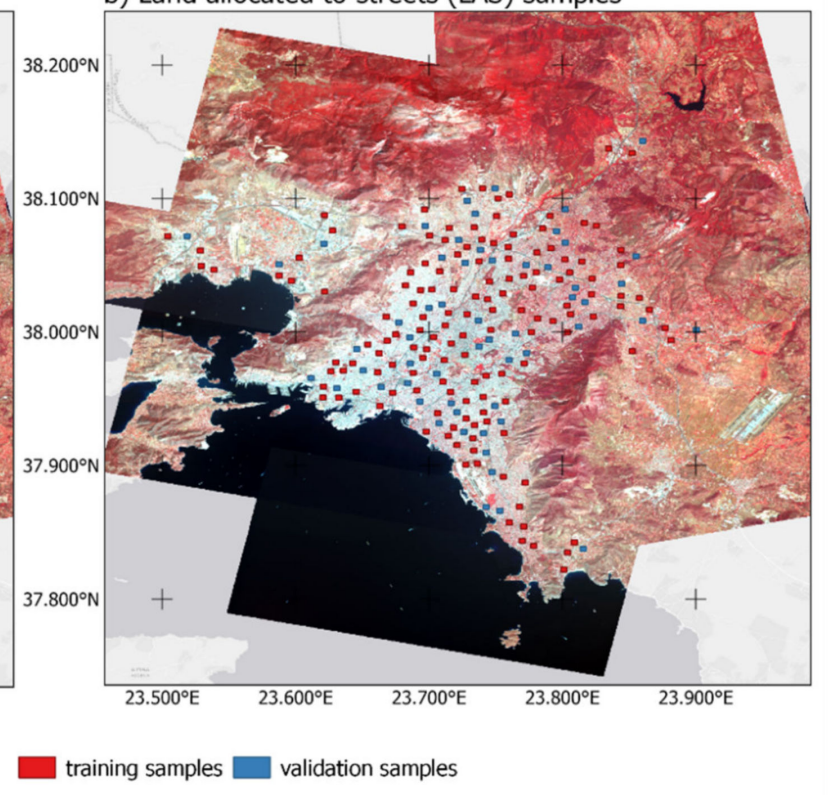

Figure 3. The PlanetScope image mosaic in the background and training and validation samples for (a) urban open spaces (UOS) and (b) land allocated to streets (LAS). Basemap: Esri.

Two experiments were conducted for mapping the UOS. In the first (experiment 1), only the four PlanetScope bands along with the NDVI image were used as features for training the network, after they were all normalized first to a $[0,1]$ range, since data normalization is crucial for accelerating the training of neural networks and for obtaining accurate results [58]. The second experiment (experiment 2) included the PlanetScope bands, the derived NDVI image and the S1-derived building height index, as a method of assessing the added value the SAR data had to offer. Regarding the network parameter settings, they were kept the same in both experiments. More specifically, the stochastic gradient descent (SGD) optimizer was used, with a 0.0001 learning rate, and the Dice coefficient was utilized as a loss function to account for the sample imbalance problem [36]. The Dice coefficient [59] is used in semantic segmentation problems and indicates the 
amount of overlap between the predicted and reference values. Values close to 0 suggest no overlap whereas values close to 1 suggest a complete overlap. The Dice coefficient is calculated according to Equation (4):

$$
\text { Dice Coefficient }=\frac{2|\mathrm{P} \cap \mathrm{R}|}{|\mathrm{P}|+|\mathrm{R}|}
$$

where $\mathrm{P}$ represents the predicted pixels and $\mathrm{R}$ refers to reference pixels. As a loss function, the negative value of the Dice coefficient was used. The network was trained for 500 epochs, with a batch size of 16 samples and the model produced at the epoch which exhibited the lowest validation loss was selected for the UOS prediction at a 3-m spatial resolution.

\subsubsection{Land Allocated to Streets}

Street widths in Athens vary across regions from $4.5 \mathrm{~m}$ to $25.5 \mathrm{~m}$ [60]. The necessity to account for this variance and in order to correctly represent the full range of LAS, led to the use of VHR PlanetScope imagery combined with a DL algorithm to map LAS in the AMA, also in this case.

In recent studies, U-NET was considered ideal for road extraction form VHR imagery. Abderrahim et al. [61] used U-NET trained for 50 epochs, with 1108 training patches of $512 \times 512$ pixel size and RGB images of $1.2 \mathrm{~m}$ spatial resolution. Zhang et al. [34] used a deep residual U-NET, cross-entropy loss function, SGD optimizer with a learning rate of 0.001 reduced by 0.1 every 20 epochs and trained for 50 epochs. They used 30,000 RGB training patches of $224 \times 224$ pixels.

Since training samples were limited in this study, the LAS problem was approached with a similar rationale as the UOS problem, by making use again of the U-NET DL architecture. Training and validation samples were created by generating 200 points, inside the calculated urban extent, of which 200 patches covering approximately $160,000 \mathrm{~m}^{2}$ $(133 \times 133$ pixels in the PlanetScope image) were generated (Figure 3$)$. Subsequently, the patches were randomly split by a 70/30 percentage ratio and 143 patches were selected for training and 57 for validation. In each patch, manual editing was performed through photointerpretation of Google Earth imagery to improve the OSM LAS vector file where needed. The corrected LAS file was finally rasterized to $3 \mathrm{~m}$ and used in the training and validation process of the network. A total of 2143 random sample patches of $65,536 \mathrm{~m}^{2}$ $\left(85 \times 85\right.$ pixels in the resampled rasterized image) were created within the $200160,000-\mathrm{m}^{2}$ patches and were used for training or validation, accordingly. Specifically, 1500 samples were chosen for training and 643 for validation purposes.

All four bands of the PlanetScope mosaic were selected as features for the training after being normalized to a [0,1] range. Regarding the network parameter settings, an Adam optimizer and the Dice loss function were used. The network was trained for 50 epochs, with a batch size of 32 samples. The model produced at the epoch which exhibited the lowest validation loss was ultimately selected for predicting the LAS at $3 \mathrm{~m}$ resolution.

\subsubsection{Accuracy Assessment and Indicator Calculation}

Two metrics were employed for evaluating the accuracy of the three networks: (a) the Keras binary accuracy and (b) the Intersection over Union (IoU). The binary accuracy reflects the frequency in which the predicted values match the reference values, with a threshold of 0.5 , in a binary classification problem. The IoU [36] is calculated using Equation (5) and in analogy to the Dice coefficient, expresses the amount of overlap between the predicted and reference values, by penalizing errors more than the Dice coefficient.

$$
I o U=\frac{|P \cap R|}{|P \cup R|}
$$

Lastly, the cross-tabulation matrix between the pixels of the resulting UOS and LAS and the respective OSM layers were produced for measuring their agreement. 
The final indicator value was calculated by computing the area of each component (UOS and LAS), their sum, and by further dividing the sum with the total area of the urban extent.

\section{Results}

Figure 4 depicts the urban extent of the AMA, delimited in the first step, as well as the UOS (in both experiments) and the LAS, as mapped in the second and third step, respectively. The resulting urban extent covers a total area of $470.439 \mathrm{~km}^{2}$. Within these boundaries, the share of built-up areas occupied by UOS was estimated at $2.72 \%$ $\left(12.797 \mathrm{~km}^{2}\right)$, when using only the PlanetScope information (experiment 1$)$, while the respective result was $9.5 \%\left(44.670 \mathrm{~km}^{2}\right)$ when utilizing the PlanetScope bands and NDVI synergistically with the $\mathrm{S} 1$ building height index.

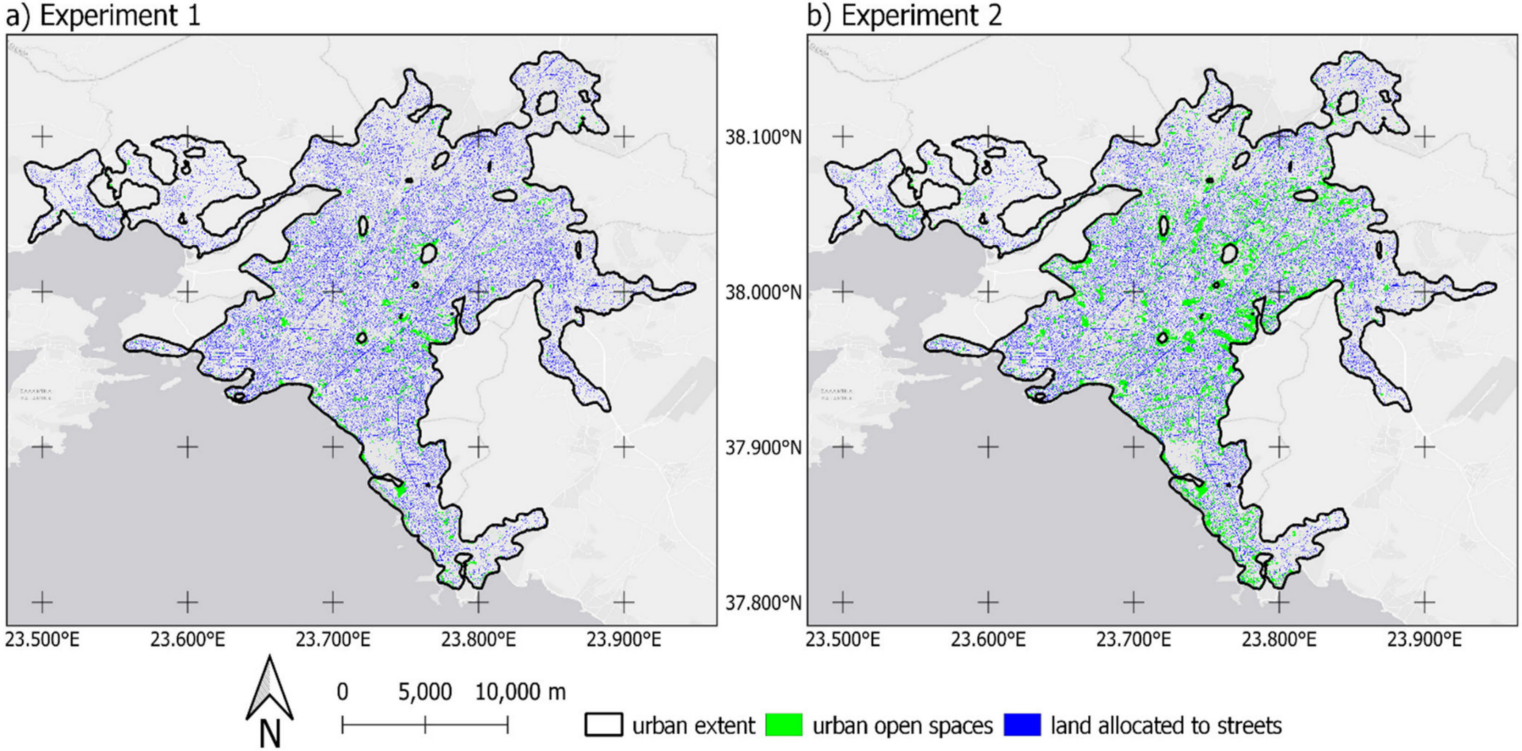

Figure 4. Urban extent of the AMA according to the UN methodology, land allocated to streets (LAS) and urban open spaces (UOS) based only on PlanetScope ((a)—experiment 1$)$ and PlanetScopeSentinel-1 data ((b)—experiment 2). Basemap: Esri.

The percentage of land occupied by streets was calculated to $13.11 \%\left(61.696 \mathrm{~km}^{2}\right)$. The final share of the built-up area of the city representing open space in public use, for the AMA, was computed by using the union of the UOS and LAS areas and was estimated at $15.75 \%\left(74.090 \mathrm{~km}^{2}\right)$, when using the UOS result from in experiment 1 , and $21.74 \%$ $\left(102.264 \mathrm{~km}^{2}\right)$, with the UOS result from experiment 2.

\subsection{Accuracy Metrics}

The U-NET network trained for predicting the UOS in experiment 1 reached the minimum validation loss at epoch 498 with a value of -0.3274 and for the training loss, -0.7771 . Figure 5 depicts the training and validation loss values for the 500 epochs for both experiments while in Table 2 the accuracy measures for the models are represented. The strong variations in the loss curve can be explained by the high variance of the UOS samples in terms of size, shape, and spectral response etc. The training and validation binary accuracy achieved at epoch 498 were 0.9817 and 0.9427 , respectively, while the training and validation IoU values were 0.4744 and 0.4675 , respectively. The training of the network lasted almost $32 \mathrm{~h}$ to run in Colab and the prediction for the whole AMA required approximately $4 \mathrm{~h}$. Overall, the time required for the entire procedure, including data transfer from GEE to Colab and vice versa, was around $40 \mathrm{~h}$, depending on the availability of cloud resources at the time of processing. 
Dice Loss for experiment 1

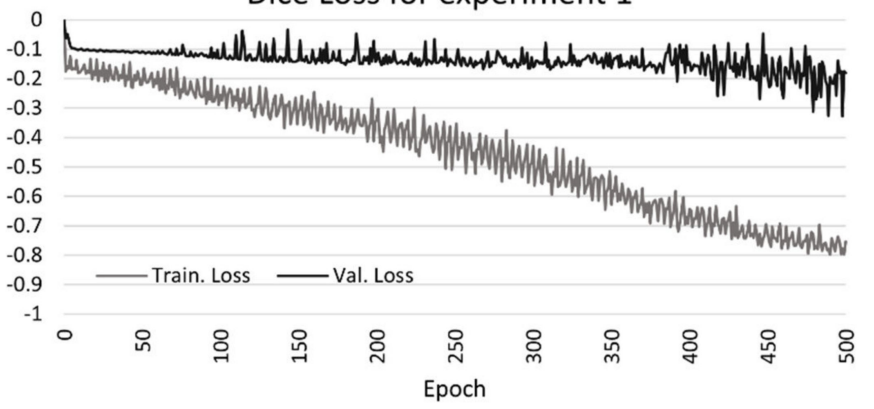

Dice Loss for experiment 2

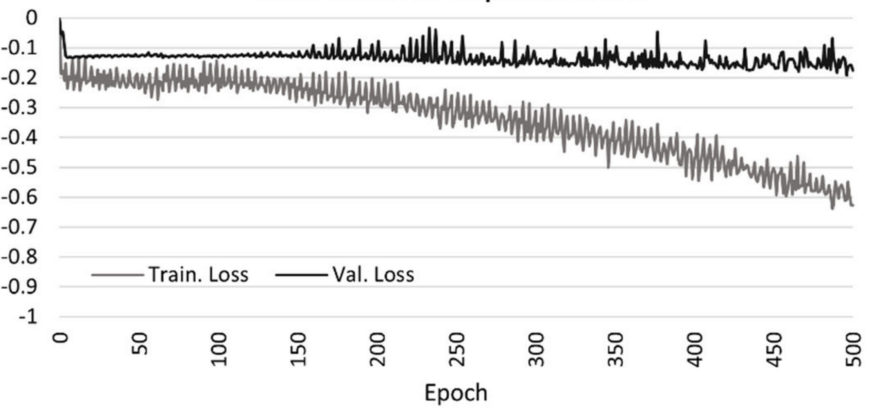

Figure 5. The training and validation Dice loss of the network for predicting the urban open spaces (UOS) in experiment 1 (only PlanetScope data) and experiment 2 (PlanetScope and Sentinel-1 data).

Table 2. Accuracy metrics for the 3 U-NET models trained for extracting land allocated to streets (LAS) and urban open spaces (UOS) based only on PlanetScope (experiment 1) and PlanetScope-Sentinel-1 data (experiment 2).

\begin{tabular}{cccc}
\hline Metric & $\begin{array}{c}\text { UOS } \\
\text { (Experiment 1) }\end{array}$ & $\begin{array}{c}\text { UOS } \\
\text { (Experiment 2) }\end{array}$ & LAS \\
\hline Train. Dice loss & -0.7771 & -0.6082 & -0.7703 \\
Val. Dice loss & -0.3274 & -0.1917 & -0.5840 \\
Train. Binary accuracy & 0.9817 & 0.9633 & 0.9442 \\
Val. Binary accuracy & 0.9427 & 0.9270 & 0.9085 \\
Train. IoU & 0.4744 & 0.4753 & 0.5835 \\
Val. IoU & 0.4675 & 0.4723 & 0.5141 \\
\hline
\end{tabular}

On the other hand, the U-NET network trained for predicting the UOS in experiment 2 exhibited lower accuracy in general, with a minimum validation loss at epoch 496 of -0.1917 and a training loss of -0.6082 . The training $(0.9633)$ and validation $(0.927)$ binary accuracies were high, while the training and validation IoU values were 0.4753 and 0.4723 , respectively. The time required for the procedure took, again, roughly $40 \mathrm{~h}$ in total.

In regard to the network trained for mapping the LAS, it reached its minimum validation loss at epoch 25 out of 50 , therefore the values of the network at this point were used for the prediction. The validation dice loss at epoch 25 reached -0.584 with a training dice loss of -0.770 (Figure 6). The training and validation binary accuracies were slightly lower compared to the UOS case (0.944 and 0.910). On the other hand, training and validation IoU values were 0.584 and 0.514 , respectively. The training of the network required around $1.5 \mathrm{~h}$ to run in Colab and the prediction for the whole AMA approximately $2 \mathrm{~h}$. Overall, the time required for the whole procedure, including data transfer from GEE to Colab and vice versa, was almost $20 \mathrm{~h}$, depending on the availability of cloud resources at the time of processing.

The cross-tabulation matrix between the unedited OSM-derived UOS layer for the AMA and the resulting UOS, for experiment 1 , revealed an intersection of only $5.555 \mathrm{~km}^{2}$ $(32.67 \%)$ with the OSM-derived UOS layer, with commission errors of $7.242 \mathrm{~km}^{2}$ and omission errors at a size of $11.447 \mathrm{~km}^{2}$, while on the other hand, the respective result for experiment 2, exhibited an agreement of $11.456 \mathrm{~km}^{2}(67.38 \%)$ followed by higher commission errors $\left(33.214 \mathrm{~km}^{2}\right)$ and lower omission errors $\left(5.547 \mathrm{~km}^{2}\right)$ (Table 3). The reference LAS layer and resulting LAS cross-tabulation showed an agreement of $38.786 \mathrm{~km}^{2}$ $\left(55.95 \%\right.$ ), with $22.910 \mathrm{~km}^{2}$ of commission and $30.537 \mathrm{~km}^{2}$ of omission errors (Table 4). 


\section{Dice Loss}

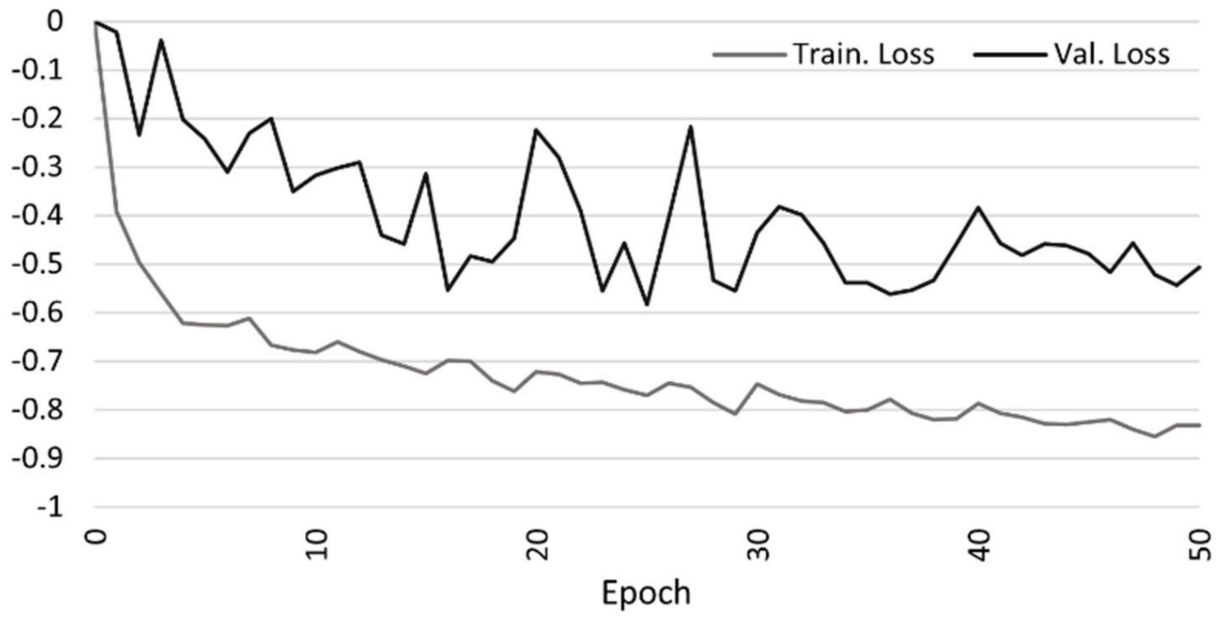

Figure 6. The training and validation Dice loss of the network for predicting the land allocated to streets (LAS).

Table 3. Cross-tabulation matrix between the OSM UOS and the resulting UOS considering only PlanetScope (experiment 1) and PlanetScope-Sentinel-1 data (experiment 2).

\begin{tabular}{|c|c|c|c|c|c|}
\hline & & \multicolumn{2}{|c|}{ UOS Experiment 1} & \multicolumn{2}{|c|}{ UOS Experiment 2} \\
\hline & & UOS $\left(\mathrm{km}^{2}\right)$ & Non-UOS $\left(\mathrm{km}^{2}\right)$ & UOS $\left(\mathrm{km}^{2}\right)$ & Non-UOS $\left(\mathrm{km}^{2}\right)$ \\
\hline \multirow{2}{*}{ OSM } & UOS $\left(\mathrm{km}^{2}\right)$ & 5.555 & 11.447 & 11.456 & 5.547 \\
\hline & non-UOS $\left(\mathrm{km}^{2}\right)$ & 7.242 & 446.073 & 33.214 & 420.101 \\
\hline
\end{tabular}

Table 4. Cross-tabulation matrix between the OSM LAS and the resulting LAS.

\begin{tabular}{|c|c|c|c|}
\hline & & \multicolumn{2}{|c|}{ Result } \\
\hline & & LAS $\left(\mathrm{km}^{2}\right)$ & Non-LAS $\left(\mathrm{km}^{2}\right)$ \\
\hline \multirow{2}{*}{ OSM } & LAS $\left(\mathbf{k m}^{2}\right)$ & 38.786 & 30.537 \\
\hline & non-LAS $\left(\mathrm{km}^{2}\right)$ & 22.910 & 378.015 \\
\hline
\end{tabular}

\subsection{Visual Assessment of Results}

The main resulting products of this study (UOS and LAS) underwent an additional visual assessment to identify errors that were not evident in the accuracy measures.

Regarding the UOS products, in general, the model of experiment 1 tended to underestimate the UOS, while the model of experiment 2 overestimated them. The resulting product of experiment 1 , proved to be weaker in representing UOS, since omission errors were observed throughout the entire AMA, not only in small open areas (metropolitan and pocket parks) (Figure 7a), but also in greener suburbs of the city (Figure $7 \mathrm{~b}$ ). Conversely, in experiment 2, commission errors were found predominantly at the greener northern and eastern suburbs of the AMA (Figure 7d), where various non-public green spaces were mistakenly classified as UOS. In addition, commission errors of UOS were found around facilities which, although public, are not open and accessible to everyone (i.e., military camps, hospitals).

Contrary to the UOS, the LAS product exhibited highly satisfactory results in most areas of the urban cluster, with errors only in industrial units of the city (Figure 8a) and in the region of the old town of Athens (Plaka) (Figure 8b), both cases in which the road network does not follow a uniform style, thus resulting in a fragmented network of streets with many omission errors. Errors were also found in densely vegetated streets in the 
north-east suburbs of Athens city. The large omission errors visible in the cross-tabulation matrix can be explained by errors existing in the filtered OSM LAS layer, even though green areas were removed. In particular, in Figure 8b, it can be seen that streets inside parks are included in the general (unedited) OSM LAS area, although they were removed from any sample patches that included them.
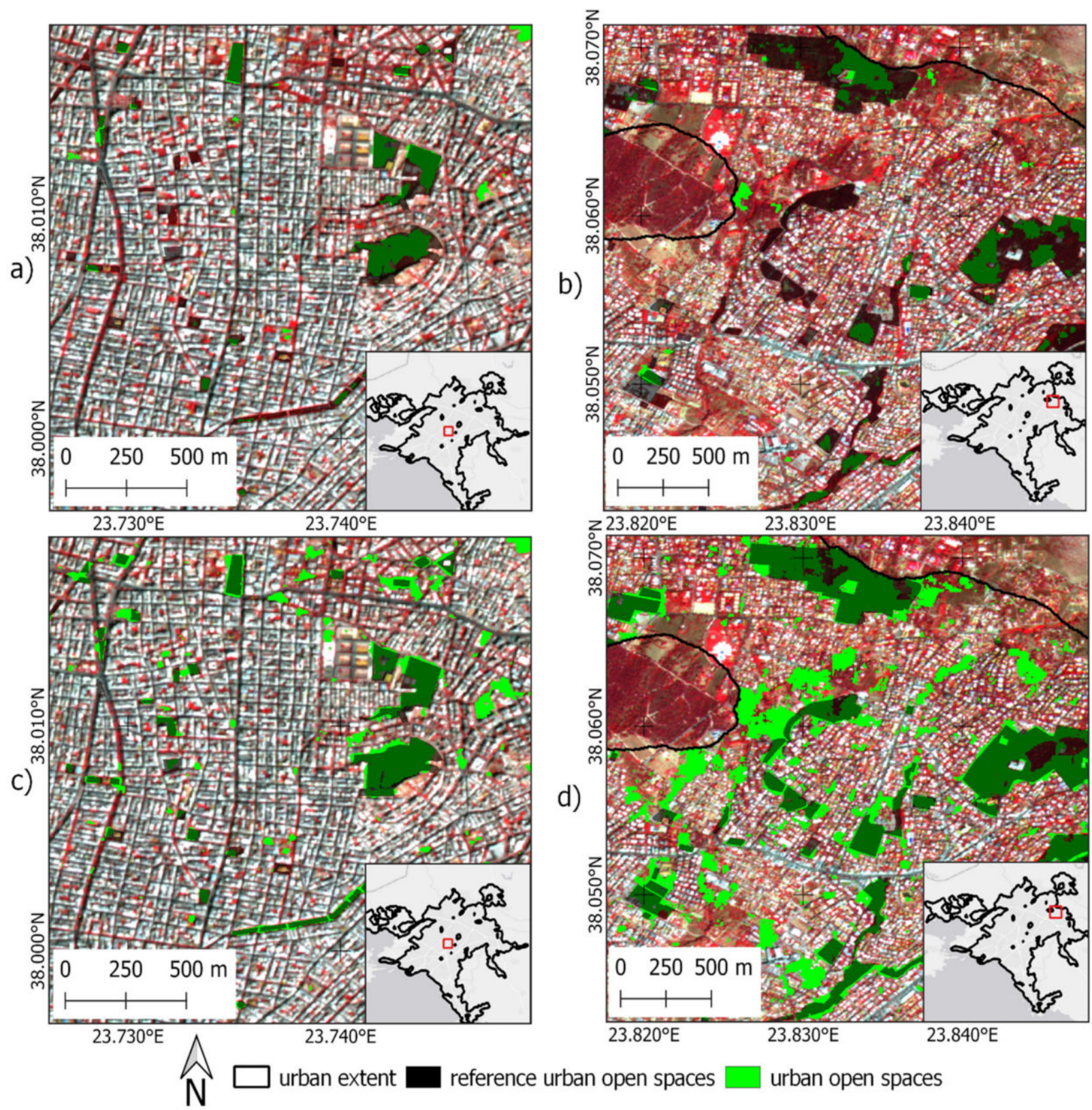

Figure 7. Urban open spaces (UOS) mapped in experiment $1(\mathbf{a}, \mathbf{b})$ and in experiment 2 (c,d), in densely built-up areas $(\mathbf{a}, \mathbf{c})$ and in green suburbs of the city $(\mathbf{b}, \mathbf{d})$. 
a)

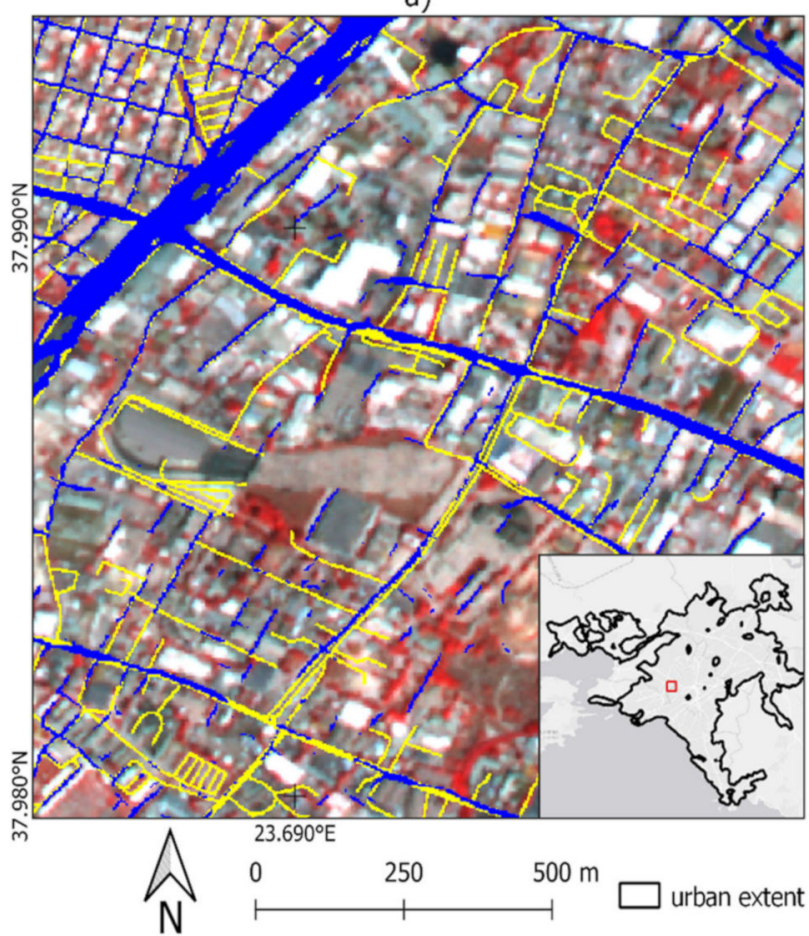

b)

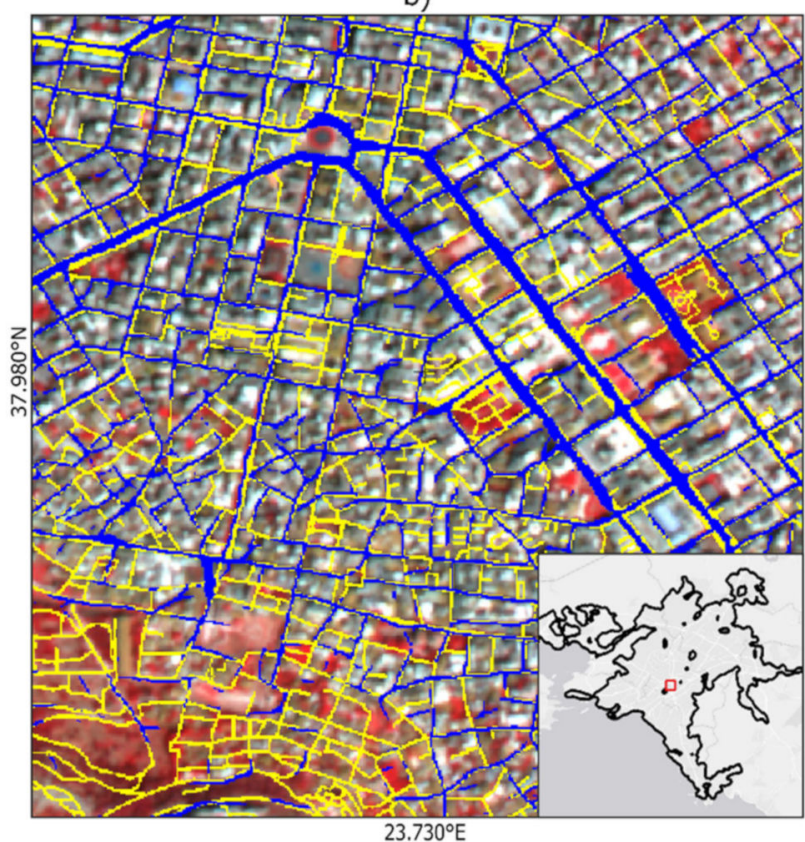

land allocated to streets $\square$ reference land allocated to streets

Figure 8. Omission errors in the LAS product in (a) the industrial region of Athens, (b) in the old city (Plaka).

\section{Discussion}

In this study, essential land use information for calculating SDG indicator 11.7.1 was quantified and spatially explicitly mapped, employing a three-step approach, using VHR PlanetScope satellite imagery and readily available EO products. Our integrated approach is, to our knowledge, the first to extract all essential land use information needed (i.e., both green and gray UOS, LAS), using EO data, for calculating indicator 11.7.1. On the other hand, previous research efforts involving EO data analysis for the SDG indicator 11.7.1 calculation, usually addressed information requirements related to green UOS [28,33,36,53], or LAS $[34,61]$ extraction. The use of DL algorithms within a free cloud computing resource further unlocks the potential of EO for providing operational and accurate information for decision making and sustainability monitoring, over urban agglomerations, compared to previous classification approaches relying on shallow learning [11].

Although the model for mapping LAS in this study proved to bear high accuracy results, with a validation dice loss of -0.584 , the UOS mapping appeared to present a much more challenging problem and yielded a validation dice loss of -0.3274 in the best trained model (experiment 1). However, despite the fact that experiment 1 yielded better results in U-NET model accuracy metrics, the cross-tabulation and visual assessment proved otherwise. The results of experiment 2, with a validation dice loss of -0.1917 exhibited higher intersecting areas of UOS with the OSM reference UOS, with the higher commission errors explained by non-public or accessible open spaces being classified as UOS (e.g., private gardens, military and hospital areas etc.), leading to the conclusion that the only limiting factor of the model was the public aspect of open spaces. Although it can be difficult to explain the mechanisms inside deep neural networks, visual comparison of the UOS results in the two experiments, can lead to the conclusion that the model in experiment 1 assigned higher weights to high-level features (contextual and geometrical information of objects), preserving the shape of UOS at their boundaries, while the model in experiment 2 exhibited higher weights in lower-level features from the building height index information, thus detecting larger UOS areas (Figure 9). This however led to a "leak" 
at the UOS boundaries (Figure 7), which could be explained by the lower resolution of the S1 data (i.e., $10 \mathrm{~m}$ instead of $3 \mathrm{~m}$ for PlanetScope data). Experiment 2 for obtaining UOS, proved that in addition to VHR multispectral data, SAR data, even in a relatively coarse spatial resolution (i.e., Sentinel-1 at $10 \mathrm{~m}$ ), through the vertical information offered in its polarized wave bands, is crucial in mapping open areas in the spectrally complex urban space. Although SAR data were used in studies focused on urban morphology [62,63], its use in urban open area extraction has not been previously tested.

a)

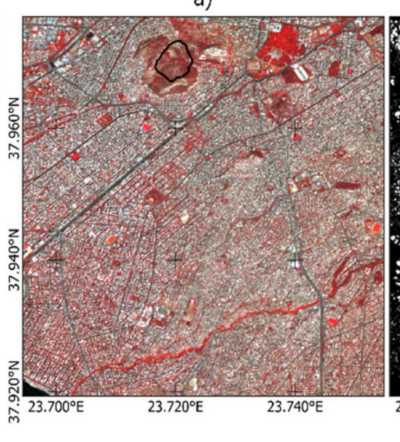

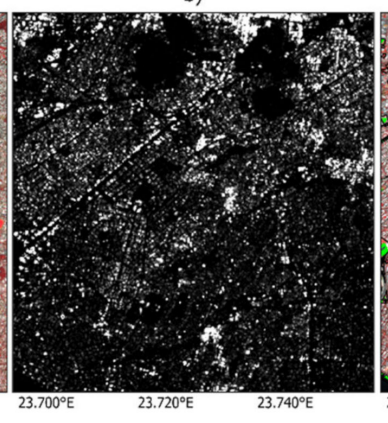

c)

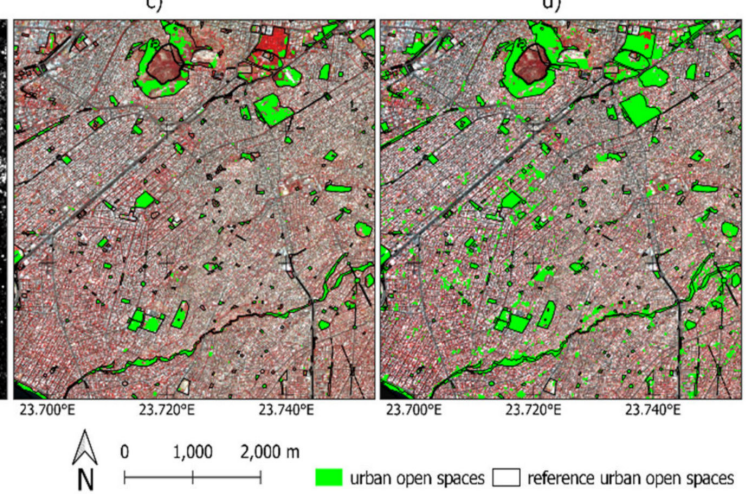

Figure 9. PlanetScope image (a), S1 building height index (b) and results of UOS in experiment 1 (c) and experiment 2 (d).

Notwithstanding the fact that higher accuracy metrics are observed in other studies, it is important to note that these results mostly refer to urban green spaces as opposed to UOS which were studied herein. The complexity and variance of open spaces in cities, along with the "noise" private open spaces cause, comprises a major challenge which cannot be solved using EO alone. The public aspect of UOS, which refers to land use rather than land cover, revealed the requirement of additional data apart from OSM to be defined, an issue also observed in other studies [11,54].

In relation to the LAS detection and mapping, our approach attained less satisfactory accuracy compared to earlier studies focusing on road extraction. This can be explained by the smaller number of samples available here and the lower spatial resolution of the PlanetScope imagery, as opposed to the 1-m resolution aerial images commonly employed in earlier studies $[34,52,61,64]$. However, the visual assessment of the LAS mapping result, strongly suggests this information layer can be used for reporting the indicator at the metropolitan or even municipal level.

While the results can quantify the prevailing tendency of UOS coverage in a city, ancillary local data and post-processing is needed in order to correctly represent UOS [65]. Nevertheless, the UOS map produced using the methodology in experiment 2 can serve as a "potential" UOS layer for further facilitating the computation of indicator 11.7.1 by statistical organizations, especially in cases where open GIS data, such as OSM, is absent or exhibits many errors.

The spatial distribution of UOS within the AMA further revealed the unequal dispersion of them, as additionally stated in [66]. Although the city has high accessibility to UOS due to its large and well-connected road network, UOS are not equally available to all citizens. Large areas of UOS are mostly located at the north-eastern and southern sections of the city, areas most inhabited by a prosperous middle- and upper-class population. Instead, the western aspect of the AMA suffers from a lack of UOS, while the regions close to the city center hold mostly smaller UOS. Therefore, it should be highlighted that indicator 11.7.1, being a ratio represented at the city level, is unable to capture differences of this nature, which express social inequalities [67]. Thus, calculations of the indicator representing detailed spatial information, such as in this study, will allow better intra-urban disaggregation to support policy making. 
Regarding the final share of open spaces for the AMA, it was estimated at $21.74 \%$, considering the most accurate case of UOS in terms of accuracy (experiment 2). Most countries worldwide have not yet officially reported the final values of indicator 11.7.1, to our knowledge, except for Germany, which in 2018 reported a value of 31.78\% [68]. Furthermore, the calculated share of all open spaces for the AMA (UOS + LAS), in both experiments, is in line with the report by the European Joint Research Center for accessibility of urban green areas [69], which reported a share of $14 \%$ by employing the European Settlement Map. The percentage of UOS and LAS estimated for Athens in this study ( $9.5 \%$ and $13.11 \%$, respectively), nevertheless remains in the low-end of national standards, considering UN-Habitat suggests a proportion of $15-20 \%$ for UOS and $30-35 \%$ for LAS for a well-functioning city [27].

Google's free Colab cloud environment, for the implementation of workflow for this study, offered a great advantage in terms of computational time, as well as direct communication with GEE's free resources and tools. Moreover, the scripts developed can be easily shared and run by other users, with minor changes in their settings, since they are not system-dependent. Consequently, the developed methodology, with the aid of massive resources of cloud environments, can be easily scaled to other Greek cities and at a national level.

The proposed workflow for mapping indicator 11.7.1 with PlanetScope and Sentinel imagery can be further improved by the integration of ancillary data for the distinction of private/public and accessible/inaccessible UOS, at a post-processing stage. Such data may include local land use maps or the use of cellphone and social network data [70], if consent to use the data is given. Future work to extend this study will integrate the transferability of the method to other Greek cities included in the National Sample of Cities and the aggregation to a municipal scale within cities, to highlight intra-urban differences and inequalities. Finally, the accessibility aspect of indicator 11.7.1 to UOS can be studied, by using network and GIS analysis of the LAS and UOS layers [12,71,72].

\section{Conclusions}

The aim of this study was to model the essential land use components required for calculating SDG indicator 11.7.1, for the AMA, based on the UN instructions and employing satellite imagery, satellite-derived products, along with open GIS information for retrieving reference data. The main processing was performed using DL, in the freely-available cloud environments of Google Colab and GEE.

The best performing model developed for mapping UOS, although exhibiting high commission errors, managed to produce a result bearing an overlap of $67.38 \%$ with the respective open areas from OSM. The developed process can thereby serve as method for creating a "potential" UOS layer for further facilitating the computation of indicator 11.7.1 by statistical organizations, especially in cases where open GIS data, such as OSM, are absent or error-ridden. Furthermore, the model for mapping LAS proved to exhibit satisfactory accuracy results, with a validation dice loss of -0.584 and an overlap of $55.95 \%$ with the respective LAS from OSM, indicating its reliability in mapping LAS, in place of the sampling technique proposed by the UN methodology for indicator 11.7.1.

This study is, to our knowledge, the first to map all land use components of indicator 11.7.1. The methodology developed herein can serve as a roadmap for the development of an end-to-end, automated workflow, for national statistical offices to calculate indicator 11.7.1 in Greece.

Author Contributions: Conceptualization and research design, N.V.; methodology, N.V. and G.M.; analysis implementation, N.V.; writing-original draft preparation, N.V. and G.M.; review and editing, N.V., G.M. and P.P.; supervision, G.M. and P.P.; All authors have read and agreed to the published version of the manuscript.

Funding: This research received no external funding. 


\begin{abstract}
Acknowledgments: The research work was supported by the Hellenic Foundation for Research and Innovation (HFRI) under the HFRI PhD Fellowship grant (Fellowship Number: 1423). We gratefully acknowledge the Planet Education and Research Program, for providing access to the PlanetScope imagery used in this study. We also wish to express our gratitude to Dimitra Papandoniou, who generously gave her time to proofreading the manuscript.
\end{abstract}

Conflicts of Interest: The authors declare no conflict of interest. The funders had no role in the design of the study; in the collection, analyses, or interpretation of data; in the writing of the manuscript, or in the decision to publish the results.

\title{
References
}

1. Pesaresi, M.; Melchiorri, M.; Siragusa, A.; Kemper, T. Atlas of the Human Planet 2016; Mapping Humam Presence on Earth with the Global Human Settlement Layer; Publications Office of the European Union: Luxembourg, 2016; ISBN 9789279620225.

2. International Expert Panel on Science and the Future of Cities. Science and the Future of Cities; International Expert Panel on Science and the Future of Cities: London, UK; Melbourne, Australia, 2018.

3. United Nations. World Population Prospects 2019: Highlights; United Nations: New York, NY, USA, 2019; pp. 1-39.

4. Wai, A.T.P.; Nitivattananon, V.; Kim, S.M. Multi-stakeholder and multi-benefit approaches for enhanced utilization of public open spaces in Mandalay city, Myanmar. Sustain. Cities Soc. 2018, 37, 323-335. [CrossRef]

5. García-Gómez, H.; Aguillaume, L.; Izquieta-Rojano, S.; Valiño, F.; Àvila, A.; Elustondo, D.; Santamaría, J.M.; Alastuey, A.; Calvete-Sogo, H.; González-Fernández, I.; et al. Atmospheric pollutants in peri-urban forests of Quercus ilex: Evidence of pollution abatement and threats for vegetation. Environ. Sci. Pollut. Res. 2016, 23, 6400-6413. [CrossRef] [PubMed]

6. Baró, F.; Chaparro, L.; Gómez-Baggethun, E.; Langemeyer, J.; Nowak, D.J.; Terradas, J. Contribution of Ecosystem Services to Air Quality and Climate Change Mitigation Policies: The Case of Urban Forests in Barcelona, Spain. Ambio 2014, 43, 466-479. [CrossRef] [PubMed]

7. Hamada, S.; Ohta, T. Seasonal variations in the cooling effect of urban green areas on surrounding urban areas. Urban For. Urban Green. 2010, 9, 15-24. [CrossRef]

8. Moreira, T.C.L.; Polize, J.L.; Brito, M.; da Silva Filho, D.F.; Chiavegato Filho, A.D.P.; Viana, M.C.; Andrade, L.H.; Mauad, T Assessing the impact of urban environment and green infrastructure on mental health: Results from the São Paulo Megacity Mental Health Survey. J. Expo. Sci. Environ. Epidemiol. 2021, 1-8. [CrossRef]

9. Ahirrao, P.; Khan, S. Assessing Public Open Spaces: A Case of City Nagpur, India. Sustainbility 2021, 13, 4997. [CrossRef]

10. United States Indicator 11.7.1. Average Share of the Built-Up Area of Cities That Is Open Space for Public Use for All, by Sex, Age and Persons with Disabilities; Eurostat: Luxembourg, 2018.

11. Aguilar, R.; Kuffer, M. Cloud Computation Using High-Resolution Images for Improving the SDG Indicator on Open Spaces. Remote Sens. 2020, 12, 1144. [CrossRef]

12. Giuliani, G.; Petri, E.; Interwies, E.; Vysna, V.; Guigoz, Y.; Ray, N.; Dickie, I. Modelling Accessibility to Urban Green Areas Using Open Earth Observations Data: A Novel Approach to Support the Urban SDG in Four European Cities. Remote Sens. 2021, 13, 422. [CrossRef]

13. Ludwig, C.; Hecht, R.; Lautenbach, S.; Schorcht, M.; Zipf, A. Mapping Public Urban Green Spaces Based on OpenStreetMap and Sentinel-2 Imagery Using Belief Functions. ISPRS Int. J. Geo-Inf. 2021, 10, 251. [CrossRef]

14. Prakash, M.; Ramage, S.; Kavvada, A.; Goodman, S. Open Earth Observations for Sustainable Urban Development. Remote Sens. 2020, 12, 1646. [CrossRef]

15. Alamanos, A.; Linnane, S. Estimating SDG Indicators in Data-Scarce Areas: The Transition to the Use of New Technologies and Multidisciplinary Studies. Earth 2021, 2, 37. [CrossRef]

16. Ferreira, B.; Iten, M.; Silva, R.G. Monitoring sustainable development by means of earth observation data and machine learning: A review. Environ. Sci. Eur. 2020, 32, 120. [CrossRef]

17. Kearney, S.P.; Coops, N.C.; Sethi, S.; Stenhouse, G.B. Maintaining accurate, current, rural road network data: An extraction and updating routine using RapidEye, participatory GIS and deep learning. Int. J. Appl. Earth Obs. Geoinf. 2020, 87, 102031. [CrossRef]

18. Zhang, C.; Sargent, I.; Pan, X.; Li, H.; Gardiner, A.; Hare, J.; Atkinson, P.M. An object-based convolutional neural network (OCNN) for urban land use classification. Remote Sens. Environ. 2018, 216, 57-70. [CrossRef]

19. Chen, B.; Tu, Y.; Song, Y.; Theobald, D.M.; Zhang, T.; Ren, Z.; Li, X.; Yang, J.; Wang, J.; Wang, X.; et al. Mapping essential urban land use categories with open big data: Results for five metropolitan areas in the United States of America. ISPRS J. Photogramm. Remote Sens. 2021, 178, 203-218. [CrossRef]

20. Habitat. The Street Connectivity Index (SCI) of Six Municipalities in Jalisco State, Mexico; United Nations: New York, NY, USA, 2016; pp. 1-66.

21. Pesaresi, M.; Huadong, G.; Blaes, X.; Ehrlich, D.; Ferri, S.; Gueguen, L.; Halkia, M.; Kauffmann, M.; Kemper, T.; Lu, L.; et al. A global human settlement layer from optical HR/VHR RS data: Concept and first results. IEEE J. Sel. Top. Appl. Earth Obs. Remote Sens. 2013, 6, 2102-2131. [CrossRef]

22. Ehrlich, D.; Kemper, T.; Pesaresi, M.; Corbane, C. Built-up area and population density: Two Essential Societal Variables to address climate hazard impact. Environ. Sci. Policy 2018, 90, 73-82. [CrossRef] 
23. Houborg, R.; McCabe, M.F. A Cubesat enabled Spatio-Temporal Enhancement Method (CESTEM) utilizing Planet, Landsat and MODIS data. Remote Sens. Environ. 2018, 209, 211-226. [CrossRef]

24. Planet Team. Planet Application Program Interface. In Space for Life on Earth; Planet Publications: Fort Mill, SC, USA, 2017. Available online: https:/ / www.planet.com/pulse/publications / (accessed on 21 January 2022).

25. Yin, J.; Dong, J.; Hamm, N.A.S.; Li, Z.; Wang, J.; Xing, H.; Fu, P. Integrating remote sensing and geospatial big data for urban land use mapping: A review. Int. J. Appl. Earth Obs. Geoinf. 2021, 103, 102514. [CrossRef]

26. Jozdani, S.E.; Johnson, B.A.; Chen, D. Comparing Deep Neural Networks, Ensemble Classifiers, and Support Vector Machine Algorithms for Object-Based Urban Land Use/Land Cover Classification. Remote Sens. 2019, 11, 1713. [CrossRef]

27. UN-Habitat. SDG Indicator 11.7.1 Training Module: Public Space; UN-Habitat: Nairobi, Kenya, 2018.

28. Chen, Y.; Weng, Q.; Tang, L.; Liu, Q.; Zhang, X.; Bilal, M. Automatic mapping of urban green spaces using a geospatial neural network. GISci. Remote Sens. 2021, 58, 624-642. [CrossRef]

29. Huang, B.; Zhao, B.; Song, Y. Urban land-use mapping using a deep convolutional neural network with high spatial resolution multispectral remote sensing imagery. Remote Sens. Environ. 2018, 214, 73-86. [CrossRef]

30. Yao, Y.; Yan, X.; Luo, P.; Liang, Y.; Ren, S.; Hu, Y.; Han, J.; Guan, Q. Classifying land-use patterns by integrating time-series electricity data and high-spatial resolution remote sensing imagery. Int. J. Appl. Earth Obs. Geoinf. 2022, 106, 102664. [CrossRef]

31. Tu, Y.; Chen, B.; Lang, W.; Chen, T.; Li, M.; Zhang, T.; Xu, B. Uncovering the Nature of Urban Land Use Composition Using Multi-Source Open Big Data with Ensemble Learning. Remote Sens. 2021, 13, 4241. [CrossRef]

32. Hou, Y.; Liu, Z.; Zhang, T.; Li, Y. C-UNet: Complement UNet for Remote Sensing Road Extraction. Sensors 2021, $21,2153$. [CrossRef]

33. Xu, Z.; Zhou, Y.; Wang, S.; Wang, L.; Li, F.; Wang, S.; Wang, Z. A Novel Intelligent Classification Method for Urban Green Space Based on High-Resolution Remote Sensing Images. Remote Sens. 2020, 12, 3845. [CrossRef]

34. Zhang, Z.; Liu, Q.; Wang, Y. Road Extraction by Deep Residual U-Net. IEEE Geosci. Remote Sens. Lett. 2018, 15, 749-753. [CrossRef]

35. Ma, Y.; Wu, H.; Wang, L.; Huang, B.; Ranjan, R.; Zomaya, A.; Jie, W. Remote sensing big data computing: Challenges and opportunities. Futur. Gener. Comput. Syst. 2015, 51, 47-60. [CrossRef]

36. Huerta, R.E.; Yépez, F.D.; Lozano-García, D.F.; Guerra Cobián, V.H.; Ferriño Fierro, A.L.; de León Gómez, H.; Cavazos González, R.A.; Vargas-Martínez, A. Mapping Urban Green Spaces at the Metropolitan Level Using Very High Resolution Satellite Imagery and Deep Learning Techniques for Semantic Segmentation. Remote Sens. 2021, 13, 2031. [CrossRef]

37. UN-Habitat. National Sample of Cities-A Model Approach to Monitoring and Reporting Performance of Cities at National Levels. 2017. Available online: https:// unhabitat.org/national-sample-of-cities (accessed on 21 October 2020).

38. Fameli, K.M.; Assimakopoulos, V.D. Development of a road transport emission inventory for Greece and the Greater Athens Area: Effects of important parameters. Sci. Total Environ. 2015, 505, 770-786. [CrossRef]

39. Georgakis, C.; Santamouris, M. Determination of the Surface and Canopy Urban Heat Island in Athens Central Zone Using Advanced Monitoring. Climate 2017, 5, 97. [CrossRef]

40. Salvati, L. Neither ordinary nor global: A reflection on the 'extra-ordinary' expansion of Athens. Urban Plan. Transp. Res. 2014, 2, 49-56. [CrossRef]

41. Google Colaboratory. Frequently Asked Questions. Available online: https://research.google.com/colaboratory/faq.html (accessed on 17 January 2022).

42. Gorelick, N.; Hancher, M.; Dixon, M.; Ilyushchenko, S.; Thau, D.; Moore, R. Google Earth Engine: Planetary-scale geospatial analysis for everyone. Remote Sens. Environ. 2017, 202, 18-27. [CrossRef]

43. Abadi, M.; Agarwal, A.; Barham, P.; Brevdo, E.; Chen, Z.; Citro, C.; Corrado, G.S.; Davis, A.; Dean, J.; Devin, M.; et al. TensorFlow: Large-Scale Machine Learning on Heterogeneous Distributed Systems. arXiv 2015, arXiv:1603.04467.

44. Chollet, F. Keras. Available online: https:/ / github.com/fchollet/keras (accessed on 1 November 2021).

45. Huang, H.; Roy, D.P. Characterization of Planetscope-0 Planetscope-1 surface reflectance and normalized difference vegetation index continuity. Sci. Remote Sens. 2021, 3, 100014. [CrossRef]

46. Kotchenova, S.Y.; Vermote, E.F.; Matarrese, R.; Klemm, F.J., Jr. Validation of a vector version of the $6 \mathrm{~S}$ radiative transfer code for atmospheric correction of satellite data Part I: Path radiance. Appl. Opt. 2006, 45, 6762. [CrossRef]

47. D'Andrimont, R.; Lemoine, G.; van der Velde, M. Targeted Grassland Monitoring at Parcel Level Using Sentinels, Street-Level Images and Field Observations. Remote Sens. 2018, 10, 1300. [CrossRef]

48. Copernicus Imperviousness. Available online: https://land.copernicus.eu/pan-european/high-resolution-layers/imperviousness (accessed on 17 January 2022).

49. OpenStreetMap. Available online: https:/ /www.openstreetmap.org/ (accessed on 17 January 2022).

50. Schultz, M.; Voss, J.; Auer, M.; Carter, S.; Zipf, A. Open land cover from OpenStreetMap and remote sensing. Int. J. Appl. Earth Obs. Geoinf. 2017, 63, 206-213. [CrossRef]

51. Vargas-Munoz, J.E.; Srivastava, S.; Tuia, D.; Falcao, A.X. OpenStreetMap: Challenges and Opportunities in Machine Learning and Remote Sensing. IEEE Geosci. Remote Sens. Mag. 2021, 9, 184-199. [CrossRef]

52. Wu, S.; Du, C.; Chen, H.; Xu, Y.; Guo, N.; Jing, N. Road extraction from very high resolution images using weakly labeled OpenStreetMap centerline. ISPRS Int. J. Geo-Inf. 2019, 8, 478. [CrossRef]

53. Le Texier, M.; Schiel, K.; Caruso, G. The provision of urban green space and its accessibility: Spatial data effects in Brussels. PLoS ONE 2018, 13, e0204684. [CrossRef] [PubMed] 
54. Cramwinckel, J. The Role of Global Open Geospatial Data in Measuring SDG Indicator 11.7.1: Public Open Spaces; Wageningen University: Wageningen, The Netherlands, 2019.

55. Overpass API. Available online: https://wiki.openstreetmap.org/wiki/Overpass_API (accessed on 17 January 2022).

56. Ronneberger, O.; Fischer, P.; Brox, T. U-net: Convolutional networks for biomedical image segmentation. Lect. Notes Comput. Sci. 2015, 9351, 234-241. [CrossRef]

57. Li, X.; Zhou, Y.; Gong, P.; Seto, K.C.; Clinton, N. Developing a method to estimate building height from Sentinel-1 data. Remote Sens. Environ. 2020, 240, 111705. [CrossRef]

58. Sola, J.; Sevilla, J. Importance of input data normalization for the application of neural networks to complex industrial problems. IEEE Trans. Nucl. Sci. 1997, 44, 1464-1468. [CrossRef]

59. Milletari, F.; Navab, N.; Ahmadi, S.-A. V-Net: Fully Convolutional Neural Networks for Volumetric Medical Image Segmentation. In Proceedings of the 2016 Fourth International Conference on 3D Vision (3DV), Stanford, CA, USA, 25-28 October 2016; pp. 565-571.

60. Tsianaka, E. The role of courtyards in relation to air temperature of urban dwellings in athens. In Proceedings of the PLEA2006-The 23rd Conference on Passive and Low Energy Architecture, Geneva, Switzerland, 6-8 September 2006.

61. Abderrahim, N.Y.Q.; Abderrahim, S.; Rida, A. Road segmentation using u-net architecture. In Proceedings of the 2020 IEEE International conference of Moroccan Geomatics, Casablanca, Morocco, 11-13 May 2013. [CrossRef]

62. Ren, C.; Cai, M.; Li, X.; Shi, Y.; See, L. Developing a rapid method for 3-dimensional urban morphology extraction using open-source data. Sustain. Cities Soc. 2020, 53, 101962. [CrossRef]

63. Wittke, S.; Karila, K.; Puttonen, E.; Hellsten, A.; Auvinen, M.; Karjalainen, M. Extracting urban morphology for atmospheric modeling from multispectral and sar satellite imagery. Int. Arch. Photogramm. Remote Sens. Spat. Inf. Sci. ISPRS Arch. 2017, 42, 425-431. [CrossRef]

64. Alshehhi, R.; Marpu, P.R.; Woon, W.L.; Mura, M.D. Simultaneous extraction of roads and buildings in remote sensing imagery with convolutional neural networks. ISPRS J. Photogramm. Remote Sens. 2017, 130, 139-149. [CrossRef]

65. Earth Observation for SDG. Compendium of Earth Observation Contributions to the SDG Targets and Indicators. 2020. Available online: https:/ /eo4society.esa.int/wp-content/uploads/2021/01/EO_Compendium-for-SDGs.pdf (accessed on 17 January 2022).

66. Papageorgiou, M.; Gemenetzi, G. Setting the grounds for the green infrastructure in the metropolitan areas of athens and thessaloniki: The role of green space. Eur. J. Environ. Sci. 2018, 8, 83-92. [CrossRef]

67. Ulbrich, P.; Porto de Albuquerque, J.; Coaffee, J. The Impact of Urban Inequalities on Monitoring Progress towards the Sustainable Development Goals: Methodological Considerations. ISPRS Int. J. Geo-Inf. 2018, 8, 6. [CrossRef]

68. DESTATIS Indicator 11.7.1. Available online: https://sdg-indikatoren.de/en/11-7-1/ (accessed on 17 January 2022).

69. Pafi, M.; Siragusa, A.; Ferri, S.; Halkia, M. Measuring the Accessibility of Urban Green Areas. A Comparison of the Green ESM with Other Datasets in Four European Cities; EUR 28068 EN; Publications Office of the European Union: Luxembourg, 2016.

70. Heikinheimo, V.; Tenkanen, H.; Bergroth, C.; Järv, O.; Hiippala, T.; Toivonen, T. Understanding the use of urban green spaces from user-generated geographic information. Landsc. Urban Plan. 2020, 201, 103845. [CrossRef]

71. Blaschke, T.; Kovács-Győri, A. Earth Observation To Substantiate the Sustainable Development Goal 11: Practical Considerations and Experiences From Austria. ISPRS Int. Arch. Photogramm. Remote Sens. Spat. Inf. Sci. 2020, XLIII-B4-2, 769-774. [CrossRef]

72. Poelman, H. A Walk to the Park? Assessing Access to Green Areas in Europe's Cities. Update Using Completed Copernicus Urban Atlas Data; European Commision: Brussels, Belgium, 2018; p. 13. 